\title{
Design and implementation of a monitoring system applied to a long-span prestressed concrete bridge
}

\author{
Helder Sousa, Carlos Félix, João Bento, Joaquim Figueiras
}

http://onlinelibrary.wiley.com/doi/10.1002/suco.201000014/abstract

Article first published online: 1 JUN 2011

DOI: $10.1002 /$ suco.201000014

Copyright (C) 2011 Ernst \& Sohn Verlag für Architektur und technische Wissenschaften GmbH \& Co. KG, Berlin

Structural Concrete

Volume 12, Issue 2, pages 82-93, June 2011 


\title{
Design and implementation of a monitoring system applied to a long- span prestressed concrete bridge
}

\author{
Helder Sousa ${ }^{\mathrm{a},{ }^{*}}$, Carlos Félix ${ }^{\mathrm{b}}$, João Bento ${ }^{\mathrm{c}}$, Joaquim A. Figueiras ${ }^{\mathrm{d}}$ \\ ${ }^{a}$ Civil Engineering, LABEST, Faculty of Engineering, University Porto \\ ${ }^{b}$ Civil Engineering, LABEST, School of Engineering, Polytechnic Institute of Porto \\ ${ }^{c}$ Civil Engineering, BRISA - Auto-Estradas de Portugal S. A. \\ ${ }^{a}$ Full Professor, LABEST, Faculty of Engineering, University Porto \\ Corresponding author: Helder Sousa; LABEST, Faculty of Engineering, University \\ Porto, Rua Dr. Roberto Frias s/n, 4200-465 Porto, Portugal; Tel.: +351225081823; \\ fax: +351225081835; e-mail: mail@hfmsousa.com
}

Currently long-term monitoring systems are mandatory in major civil engineering structures like bridges, tunnels and dams. Generally, they monitor a set of physical, chemical and mechanical parameters in critical sections of the structure by incorporating appropriated sensors. The set of collected data demonstrates great potential in the prevention of damage and contributes to a more efficient maintenance of the monitored structures.

This work presents the long-term monitoring system installed in the new Lezíria Bridge over the Tagus River in Portugal. The system was developed to control some aspects of the construction process and to survey the service life of the structure. A set of structural, durability and environmental parameters defining the bridge condition are remotely assessed in real time via a fiber optic network. Aspects like architecture, installation and functionalities of the monitoring system are discussed and the innovative aspects of the implementation are highlighted.

In this context, the main goal of this work is to present the long-term monitoring system of the Lezíria Bridge, sharing the experiences, the solutions and the procedures adopted, given their potential usefulness in the implementation of similar projects.

Keywords: Long-term surveillance, concrete bridges monitoring system, system implementation, project management 


\section{Introduction}

A current major concern related to large infrastructures is the increasing age they already exhibit and the implied inspection and maintenance costs. A major focus regarding this matter has been awarded to bridges and high-rise structures [1]. Bridges, in general, are experiencing accelerated deterioration and are becoming more and more exposed to wear and tear as time progresses because they were designed when the demand for transportation facilities was not as high as it is today. The vehicles' weight and the traffic increase are critical aspects [2]. The maintenance works related to structural problems like joints and bearings are critical because experience has shown that these are the equipments that suffer from premature wear, thus requiring careful and regular maintenance procedures [3]. Other common problem in bridges is the loss of sediments around and under the bridge footing due to scour that can lead to excessive pillar movement, creating an unwanted stress in the bridge structure that may eventually lead to failure or collapse [2]. The human error is also a critical issue in the structures healthy. In Korea several man-made disasters were registered in the 1990s, as a consequence of the country modernization without a corresponding integrative moral basis [4].

In the case of long-span bridges, the effectiveness of visual inspection in reaching all the critical locations and in finding all the possible defects becomes especially questionable. In the United States, a study by the Federal Highway Administration (FHWA) revealed that at least $56 \%$ of the average condition ratings were incorrect with a 95\% probability from the visual inspection (2001). It follows that if health monitoring could be designed and implemented as a complement to visual inspection, to enhance its effectiveness and mitigate its shortcomings, bridge owners would be decided to take advantages of this new paradigm [5]. 
Structural Health Monitoring (SHM) is a subject of major international research.

While in the past, this topic was mainly addressed from the angle of sensors, now the practical implications regarding the acquisition, collecting and processing of data are being addressed [1]. Today it is possible to monitor continuously and remotely highly instrumented structures, with a high degree of automation. Present solutions are versatile enough to allow for surveillance tasks to be released remotely with sound cost effectiveness [6]. This is performed by measuring a set of physical and chemical parameters with appropriate sensors, which allow the permanent control of critical parameters through a compatible acquisition and communication system, allowing the automatic and remote storage in a database, often accessible through the Internet. In general, continuous measurement at low frequencies for long time (e.g. hourly measurements) would be needed to capture the trends in climate- and weather-related inputs, changes in ground and soil, the movements of the foundations and of the superstructure. Programmed, as well as triggered intermittent, measurements would be needed for shorter periods at higher frequencies for capturing operational and the corresponding structural parameters [5]. Over the past decade there have been several full-scale demonstration projects that have involved varying degrees of structural health monitoring technologies for short- and long-span bridges [5]. In a European research project - Smart Structures [7], innovative and inexpensive probes for monitoring existing concrete structures were developed, tested, and integrated in a monitoring system to reduce the inspection and maintenance costs and the traffic delays [1]. In Hong-Kong and China the SHM is currently included as a standard mechatronic system in the design and construction of most large-scale and multidisciplinary bridge projects [8]. 
In this context, it is important that new bridges are equipped with monitoring systems from the beginning of their operation. It is envisioned that the cost of the monitoring system and the perpetual cost of its maintenance are expected to protect the much higher investment in the bridge construction and its operating costs [5]. Monitoring the condition of an existing highway bridge structure helps to ensure its safety with regard to life extension and replacement strategies [6].

This work presents the monitoring system implemented in a recent bridge built in Portugal - The Lezíria Bridge. The main scope is to show how a complex process, related to the implementation of a monitoring system, was guided to obtain the intended solution. After a general description of the bridge, the monitoring system is detailed in three main parts: (1) the process, where issues related with sensors type, acquisition systems and communications to a remote database are described; (2) the installation, with reference to laboratory works and some of the most complex and peculiar field works related with the sensors installation; and (3) the records, referring the reading procedures adopted and how this information is organized and delivered to the bridge owner.

\section{The Lezíria Bridge}

\subsection{The socio-economic context}

The Lezíria Bridge, constructed between 2005 and 2007, is inserted in the A10 Highway Bucelas / Carregado (A1) / IC3 (A13). With a total length of $39.9 \mathrm{~km}$, this highway is an outside bound to the Lisbon Metropolitan Area. It benefits to those who wishing to travel to or from Alentejo or the Algarve (A2 highway) and Spain (A6 highway), without crossing the Portugal capital - Lisbon. In addition, this new bridge will improve the accessibility between Vila Franca de Xira and the Samora 
Correia/Benavente locations leading to a substantial traffic relief in the national roads EN10 and EN118 [9].

\subsection{The Structure}

The 11,670 m total length of the Lezíria Bridge are materialized by three substructures: (1) the north approach viaduct with $1700 \mathrm{~m}$ of length; (2) the main bridge substructure, crossing the Tagus river, with a total length of $970 \mathrm{~m}$; (3) and the largest substructure, the south approach viaduct, with a total length of $9160 \mathrm{~m}$. Figure 1 illustrates the construction stage of the three substructures.

\subsubsection{North approach viaduct}

From the three substructures, the north approach viaduct provides the connection to the A1 highway. The north viaduct structure has three elementary girder viaducts, with current spans of $33 \mathrm{~m}$ of length, except at the crossing with a railway line in which the largest span has $65 \mathrm{~m}$ and is partially formed by a box girder. The viaduct deck is supported by pillars-pile with length that can reach $40 \mathrm{~m}$ deep. The railway line that crosses the north viaduct and the existence of an electric power plant and a neighbour substation were constraints considered in the project [9].

\subsubsection{Main bridge}

The main bridge structure is formed by 8 spans and 7 pillars supported by pile caps over the river bed. The spans length is $130 \mathrm{~m}$ except the end spans, with $95 \mathrm{~m}$, and two of the mid spans that differ in $5 \mathrm{~m}$ due to a change in a pillar implementation leading to spans with $125 \mathrm{~m}$ and $135 \mathrm{~m}$ of length. The bridge deck is materialized by a box girder of variable inertia with about $10 \mathrm{~m}$ of width and heights varying between 4 $\mathrm{m}$ and $8 \mathrm{~m}$. The box girder core construction was made by segmental construction using a movable scaffolding while the side consoles were subsequently constructed 
sustained by a different movable scaffolding and metallic struts fixed in the bottom slab of the box girder, as it is illustrated in Figure 1-b. The concrete pillars are formed by four walls with constant thickness and variable width and are supported by pile caps ( 8 piles in general and 10 in the two pile caps bounding the navigation channel).

\subsubsection{South approach viaduct}

The south approach viaduct has 22 elementary viaducts with extensions ranging from $250 \mathrm{~m}$ to $530 \mathrm{~m}$. It has a span length of $36 \mathrm{~m}$, with exceptions due to the existence of irrigation canals and dikes in the Lezíria fields. The deck floor is supported by precast beams executed in the construction site, where a precast industrial unit was specifically built, being the precast elements monolithically linked to the pillars. The viaduct deck is formed by precast slabs, supported on the precast beams, and serving as formwork to the in situ top concrete layer. Like the north viaduct the viaduct deck is supported on pillars-pile with lengths varying from $35 \mathrm{~m}$ to $60 \mathrm{~m}$ deep, given the need for crossing alluviums with variable constitution.

\subsection{The monitoring system main concepts}

A project like the long-term monitoring system of the Lezíria Bridge is complex and has a broad scope. Nevertheless, it may be unfolded in a sequence of three main stages: (1) The process, which includes all the development stages until the execution, finalising with the document for execution - Executive Project; (2) The installation, which includes all the work tasks that allows the full implementation of the Executive Project; (3) The records, organized as a database representing the final product. In the area of bridge monitoring, the long-term monitoring system of the Lezíria Bridge presents a number of innovative aspects in comparison to other bridge monitoring projects. The structural and durability monitoring project is part of the 
bridge design tasks from the beginning, through a specific project volume entitled "Structural and Durability Monitoring Plan" [10]. As part of that project volume, the long-term monitoring system was subjected to successive versions with the participation of different entities, such as the bridge owner, the designer, the contractor, various consultants, and SHM ("Structural Health Monitoring") experts, in order to bring together and coordinate a variety of interests and points of view. The final version of the monitoring system project, the Executive Project, by its organization, contents and objectives, demonstrates to be a reference document in the structural and durability bridge monitoring in Portugal. After the specification and process definition phase, the installation of the monitoring system has started. During approximately eighteen months a highly specialized work team lead a long journey of installation tasks. The key for the successful installation of the monitoring system resulted from the know-how, dynamism, flexibility, adaptability and common understanding qualities of the team.

The obtained results are an essential source of knowledge, in its present state, providing a valuable basis for further research in the domain of structural monitoring. That source of knowledge presents a great potential both for the damage prevention and for the management of the monitored bridge.

\section{Monitoring system of the Lezíria Bridge - The process}

The Executive Project of the Structural and Durability Monitoring Plan was fully defined as a set of structured documents. Those documents, although prepared exante, have been finished along the implementation phase, following a so called "opening drawers" process [11]. Each document has a defined objective and a chronological relation with the other documents as it is specified in Table 1. 
Following this concept, the process evolved in a timely manner and it was completed step by step, with a set of clear intermediate objectives, until final delivery to the owner. The process organization took into account some special features of these systems, in particular issues related to its conclusion. The finalization of such process does not necessarily coincide with the installation of all equipments, cables and devices. Operational conclusion occurs effectively only after a certain period, counted after the physical installation. In that time interval the installed monitoring system is submitted to a meticulous validation process.

In what concerns the monitoring system, it integrates all the electrical/electronic components, sensors, automatic acquisition system and data treatment/management through an optical fibre communication network that also enables remote access. Such system has an high degree of complexity, which has three main components: a) sensorial component, b) communication component, and c) data treatment and management component (Figure 2). This architecture offers the client a set of continuous and simultaneous records of the observed parameters with capabilities for surveillance and prevention of structural safety and durability [11].

The document "A - Project brief" [12] makes a detailed description of the adopted monitoring system, with special attention to the sensors and acquisition systems selection, the communication network, the integration of all systems, as well the data treatment and the management software (Table 1).

\subsection{Sensorial component}

Considering the structure to monitor, and what is intended to measure, a number of critical points are selected for monitoring a set of parameters. In this context, the sensorial component is based on the installation of, on one hand, appropriate sensors 
to perform the measurements and, on the other, compatible acquisition systems to perform the signal processing and store the readings.

In the case of the Lezíria Bridge, the instrumentation consisting in those sensors and acquisition systems is distributed in a number of structure zones. In greater depth: two zones of the north approaching viaducts, in the whole of the main bridge length and in four zones of the south approaching viaducts, are instrumented. A set of instrumented sections defines a monitored zone and the corresponding acquisition system to interrogate the sensors is called Acquisition Node (AN). A set of sensors is installed in each section to measure the intended parameters. Suitable cables perform the connection of the sensors to the acquisition systems, with the connection nodes made in Junction Boxes (JB) and Signal Connection Boxes (SCB) as shown in Figure 3 [12].

Figure 4 illustrates the sensorial component with an identification of the measured parameters, with reference to the project symbols and adopted abbreviations, as well the types of the acquisition systems adopted to interrogate the signal of the sensorial component.

\subsubsection{Static acquisition system}

The static acquisition system interrogates $80 \%$ of the total number of the installed sensors. Consequently, the monitoring system adopted in the Lezíria Bridge is oriented towards long term monitoring. Strains, rotations, displacements, corrosion, scour, and environmental parameters are those considered for static monitoring

(Figure 4). With the obtained records it is possible to analyse the structure from the point of view of its behaviour to environmental effects - like temperature and relative humidity -, time-dependent effects - like shrinkage, creep and prestressing losses - as well the interaction between the structure and the surrounding soil. 
All these sensors are interrogated by the same acquisition system group, wherein it is possible to define reading procedures, with options available for defining the acquisition frequency of each sensor, for ordering the records sequence and storing those records in data files.

\subsubsection{Dynamic acquisition system}

The number of sensors interrogated by the dynamic acquisition system represents about of $5 \%$ of the total number of installed sensors. The main goal of these sensors is to monitor the accelerations induced in the structure and surrounding soil, caused by earthquakes or by boats collisions. With the adopted configuration it will be possible to analyse the energy transmitted from the soil to the structure, and its dissipation effects on the structural elements. The possibility of identifying the occurrence of those events by the dynamic system can provide valuable information for the interpretation of the long term behaviour when changes in the pattern of evolution in time can be justified by those events.

To measure the accelerations in a specific point (structure or soil) triaxial accelerometers are used. Those sensors measure and record the accelerations in three orthogonal directions, being connected to the acquisition system by armoured cables, specifically manufactured for this type of devices. An acquisition system supplied by the same manufacturer performs the sensors' interrogation. The software managing the dynamic acquisition system allows the alarm levels definition to each sensor and/or measurement axis, and such alarms can be sent to a particular address as IP message.

\subsubsection{Optical acquisition system}


The last decade has witnessed large developments in the application of optical fibre sensors, in particular Bragg gratings sensors in civil engineering structures [13] [14]

[15]. With recognized advantages such as the immunity to electromagnetic fields and low signal losses, and also due to the application of multiplexing techniques - where signals of multiple sensors can be carried through a single optical fibre -, Bragg sensors enabled one of the most promising sensing technology for using in civil engineering structures [6]. With this technology it is possible to encapsulate high lengths of optical fibres carrying the signals of various sensors to one acquisition system located at a specific point [12].

An optical acquisition system based on the referred Bragg gratings sensors was installed considering the referred properties and the socioeconomic importance of Lezíria Bridge. The sensors, specifically developed for this purpose [16], are an integral part of the structural and durability monitoring system. They represent the remaining $15 \%$ of the total installed sensors measuring vertical displacements, strains and temperatures [12].

The sensors' interrogation is performed by a compatible acquisition system. The management software for the readings of the optical sensors was developed based on the software of the manufacturer's acquisition system [17]. The optical acquisition system aims at expanding the information about the main bridge structural behaviour, and also at comparing the efficiency of this system with the electrical monitoring system [12].

\subsection{Communication component}

Because of the bridge length, the Acquisition Nodes (AN's) of the monitoring system are physically distant from each other. As an illustration, the distance between the two extreme AN's is about $8 \mathrm{~km}$. Consequently, a local communication network was 
installed, allowing for the integration and centralization of the information recorded by the different AN's in a single place, called the Central Acquisition Node (CAN). The option for a local communication network has simplified the remote access to the monitoring system, by allowing access to every device of the system through a single CAN. The communication network, also in optical fibre, has two rings with nine nodes (one for each of the nine instrumented zones) matching the various AN's as it is schematically shown in Figure 5.

The Lezíria Bridge is part of the motorway network operated by BRISA. It is, accordingly, included in BRISA's sophisticated communications network, covering the whole of its motorway system. In order to enable remote access to the bridge monitoring system, a link was established between the local communication network and BRISA's communication network. A dedicated server installed at BRISA's Operations Control Centre, manages this link and allows for direct and permanent communication with the CAN (Figure 5).

\subsection{Data treatment and management}

A dedicated software module was developed for data treatment and management purposes. It also provides the main database updating functions and enables the visualization of results. In addition, the system has a consultation module covering the technical information about the installed system [12]. In what concerns data treatment, the data updating module distinguishes durability and dynamic parameters from the remaining ones, with a specific procedure available for each case [12]. From a previous selection of sensors, the visualization module delivers results in both table and graph forms. The graphics allow for the observation of the time pattern of the selected sensors, individually or grouped by monitored sections. The consultation module provides all the technical information about the monitoring system installed 
such as the location of the instrumented sections, and a description of the sensors installed in each one. Additionally, it is possible to create data files in text format for external processing, as well as to automatically generate reports with the intended graphical results. Moreover, the software is prepared to notify the bridge owner by email, if the values measured by the sensors exceed the threshold values previously defined by the bridge designer [12].

\section{Monitoring system of the Lezíria Bridge - The installation}

The guidelines for the installation of the monitoring system were the documents of the Executive Project: "A - Project brief" [12], "B - Contract Drawings" [18] and "C Specifications and Procedures" [19]. The document "C-Specifications and Procedures" was specifically developed to guide the installation works, taking into account the dimension and complexity of the monitoring system. This project document, prepared to anticipate and organize a set of tasks to be carried out during the installation works, covered aspects such as: (1) the organization of laboratory tasks in order to minimize the field works; (2) the sequence and the interdependence of the in situ work to minimize the repetition of procedures; (3) the phasing of construction tasks, in order to anticipate scenarios, optimizing allocation of resources and minimizing human efforts.

\subsection{Preparation and organization of laboratory works}

The success of the in situ installation depends heavily on the preparatory work done in laboratory. To prepare the equipment and organize cables and accessories it is essential to have a strong laboratory team. A set of normalized verification procedures has to be applied to all equipment, cables and accessories, no material should leave the laboratory without passing through them. Figure 6 illustrates normalized 
procedures considered in the preparation and organization of laboratory work, including (a) calibration and verification of sensors; (b) setup of interfaces for the in situ installation of sensors; (c) preparation, identification and protection of cables.

\subsection{Bridge instrumentation}

To monitor a concrete bridge during its service life, the system installation may be implemented in two separate steps: firstly, all the embedded sensors are installed during the concreting phases; upon concreting completion, all the complementary work to conclude the installation is performed. However, in the presence of a monitoring requirement during the bridge construction, the installation of Provisional Acquisition Nodes (PAN's), in addition of the embedded sensors, is compulsory. Moreover, cabling rails and connections for the construction phase are also provisionally placed. Thus, a truly temporary monitoring system is put in place, as part of the first installation step.

Given the importance of the Lezíria Bridge, the monitoring process has covered the construction period. With that propose, three of the nine instrumented zones were monitored during the bridge construction. This fact required a great commitment of the installation team to follow the rhythm imposed by the construction works (often 24h/day), and, at the same time, to obtain successful recordings. From the above, it becomes evident that monitoring projects addressing construction phases imply stronger complexity and demand higher commitment from the installation teams, that those intended to monitor the service life only. Figure 7 illustrates some of the first monitoring works, done during the construction of Lezíria Bridge, where it is highlighted (a) the embedded sensors installation, (b) the provisory Acquisition Node installation, (c) the provisory cables path and (d) provisory connections. It is 
mandatory the anticipation and preparation of all necessary procedures to guarantee a robustness installation to face the aggressiveness of the concrete operations.

Independently of the bridge being monitored during construction, the installation of the embedded sensors is followed by a short period for the implementation of the permanent monitoring system, which, generally coincides with the finishing works of the bridge. As presented in Figure 8, the monitoring system implementation requires additionally (a) the installation of the external sensors, (b) the definitive installation of the acquisition nodes, (c) the cables passing through the technical rails and pipes and (d) the execution of the connections boxes.

The bridge finishing is the most intensive working period with the simultaneous presence of multiple work teams to fulfil all sorts of diversified works required to be finished before the inauguration date. This fact leads to increase pressure upon the installation works, thus forcing longer daily working periods. At this stage, capabilities such as dynamism, flexibility, adaptability and integration, are crucial to the success of the system installation.

Given its particular complexity or peculiarity, the installation of some sensors deserves a special mention. That is the case of (1) the piles strain gauges, (2) the soil accelerometers, (3) the sonar in the pile heads and (4) the vertical displacement system.

\subsubsection{Pile strain gauges}

Twelve strain gauges were installed inside a pile of the main bridge in a rather singular fashion. After the pile execution the installation was made in three main phases: (1) installation of the vibrating wire strain gauges using steel bars with an appropriate fixing system to place the transducers inside the holes left for crosshole acoustic tests, at three different levels (1,5 and $35 \mathrm{~m})$; (2) after the initial works for 
the pile head execution, the strain gauges were tested immediately before the holes' sealing; (3) the cables previously placed at the pile top (to avoid connections inside the concrete) were conducted through the pile head up to the pillar base. Figure 9-a presents the placement of one of those sensors in the hole

\subsubsection{Soil accelerometers}

The accelerometers installed in the soil were inserted in a borehole through an inclinometer tube, and positioned at different depths (in a range of $1 \mathrm{~m}$ to $40 \mathrm{~m}$ ) with a final cement sealing in order to get a good connection with the surrounding soil [12] [18] [20]. This installation was particularly difficult because the sensors were installed with the total cable length necessary to reach the AN on the bridge deck. This option had the advantage of avoiding additional wire connections, but required the previous passing of cables through the inclinometer tube to the acquisition system node. To illustrate the effort involved, the longest cable had more than $300 \mathrm{~m}$ and its pathway developed, sequentially, trough (1) a cable trench, (2) a pipe installed along the height of a pillar, (3) along the technical paths of the border deck, and finally (4) inside the box girder of the main bridge up to the acquisition system. Figure 9-b illustrates the placement of one of those inclinometer tube along the borehole, with the accelerometer previously and rigidly positioned at the end of the tube.

\subsubsection{Sonars}

The sonar devices were installed after the bridge construction due to the singular conditions during the construction period in the piles head (placement of scaffolding and the backrest of boats to support the construction). In order to prevent the impact of objects dragged by the river or boat collisions, the mechanical protection of the sensor and its maintenance were crucial aspects considered in the installation. The 
sonars were installed at the bottom of the pile heads upstream side. To place it in its resting position, the sonar was fixed to the extremity of a metallic tube inserted in stainless steel profile specifically designed to protect the sonar setup. Figure 9-c shows the positioning of one of the sonars inside the stainless steel tube..

\subsubsection{Vertical displacement system}

A liquid levelling system was installed along the entire length of the main bridge to allow the measuring of the vertical displacements (deflections and settlements). For that propose, a specialized team installed a hydraulic circuit after the finishing of the main bridge box girder. After installation, the pile system was filled with water and dully purged for possible air inside the hydraulic circuit. Finally, the sensors were installed and connected to the hydraulic circuit, after which a calibration routine was performed by varying the circuit water level to ensure the adequate performance of the system. Figure 9-d illustrates one of the containers fixed to the girder wall as well as the hydraulic circuit and the reference sensor.

\subsection{Testing and final checks}

Before delivering the monitoring system to the owner, a series of final tests and checks were performed in order to verify its full performance. Those tests and final checks are crucial for the identification and correction of any anomalies occurred during installation, given the well known aggressiveness of construction environments. Several tests are performed, namely: (1) signal verification of all sensors; (2) verification of the cables integrity; (3) verification of the acquisition systems up-state; (4) verification of the communications and data transmission to the Operations Central. After the conclusion of the tests and final verifications, the monitoring system is considered ready to operate in full mode. 


\subsection{Image manual, waterproofing and sealing}

At this stage, it was possible to produce, an image-based manual. The layout of this manual aims at offering a comprehensive vision and to provide an easy perception of all equipments of the monitoring system. Moreover, it facilitates future interventions on the system, as described in [18] the so called Image Manual is, in fact, a set of identification plates, plastic sheets and user manuals.

As a finish work, the connection boxes were all waterproofed to maximizing system up state and durability. Finally, the entire system was sealed to prevent and trace any unauthorized interventions that would otherwise not be easily detectable. Figure 10 illustrates some finishing works, where it is highlighted (a) the identification plates provided for an external sensor protected by a protection box, (b) plastic sheets with useful information about the monitoring system inside an Acquisition Node box, (c) waterproofing the tubes entering in an Acquisition Node and (d) a sensor sealing to prevent unauthorized access.

\section{Monitoring system of the Lezíria Bridge - The records}

\subsection{Reading procedures}

The records obtained so far are defined by reading procedures previously established according to the project objectives. For the static parameters resulting from interrogation by the electrical acquisition system, the sampling rate adopted is one sample every 3 hours, in normal mode. In alarm mode the acquisition frequency can be increased to one sample per minute. In the case of the dynamic parameters, the accelerometers sampling rate is established in $200 \mathrm{~Hz}$ by default and the system is permanently in alert, where the sensors readings are continuously saved in a ring buffer. If an alarm level is reached an event occurs and the system creates a set of files 
with the respective sensors readings and a warning message. For the optical sensors the sampling rate adopted is one sample every 3 hours in normal mode state. The acquisition frequency can be increased up to $500 \mathrm{~Hz}$ in the case of the fiber optic strain sensors in alarm mode [17]. Table 2 presents the monitored parameters with reference to the sensor type, acquisition system type, sample rate acquisition, bridge zones where sensors are installed and their purpose, as well as the thresholds for surveillance and alarm levels defined by the bridge designer [10]. The threshold values for some parameters have not been defined yet (n/d in Table 2), being their evaluation based on the first years of observation.

\subsection{Monitoring records}

As previously mentioned, the monitoring system of the Lezíria Bridge operates since the installation of the first sensors, thus enabling monitoring of the structural behaviour during construction. Along this period, it was possible to monitor some construction operations, such as: (1) concreting operations; (2) prestressing; (3) falseworks disassembly and movements of the movable scaffolding used for segmental construction (main bridge); (4) application of forces at the closing sections (main bridge); (5) load tests for structural behaviour conformity, at construction completion.

After the bridge finish and with the monitoring system in full operation, some effects concerned with the service life of the structure have been monitored, namely: (1) environmental effects; (2) shrinkage and creep evolution; (3) load traffic effects.

By contractual commitment, during the construction phase a set of periodic observation reports were delivered to the bridge owner twice a week. Those reports included (1) drawings with the positioning of all installed sensors; (2) the main events organized as a schedule; (3) time series charts of the recordings and (4) summary 
tables with the main statistical results. Figure 11 illustrates the information included in the periodic observation reports delivered twice a month during the bridge construction. This task allowed for a closer checking of the monitoring system during its installation and has revealed to be useful in evaluating the structural response during the construction process, which is one of the most important stages of the structure's life. Since opening to traffic, an observation report including all the sensors' records and main statistical information is delivered every semester to be analyzed and accounted for.

Although the bridge maintenance includes comprehensive visual inspections every 6 years, the sensors readings are extra knowledge to help in the interpretation of damages identified in the visual inspections. Moreover, the monitoring system is permanently informing about the bridge performance, reason why if abnormal values are read at any time between those 6 years campaigns, the owner is able to proceed to an extraordinary visual inspection, to facilitate interpretation of the situation. Likewise, if during a regular visual inspection any given pathology is noticed, the owner can resort to the model and to the history of measured data, as to promote a better interpretation of the situation at hand.

\section{Conclusions}

The present paper described in detail the procedures related to the design and installation of a concrete bridge monitoring system spanning from construction to life cycle surveillance. The project complexity and its scale were thoroughly illustrated adopting a hands-on approach and reflecting an implementation perception. Several hierarchical stages had to be crossed to turn this system into a physical and manageable reality, with emphasis in three fundamental phases: 
(1) A conceptual design based in a set of structured documents. Due to the system complexity, these documents were crucial for the following work stages. The definition of intermediate objectives was an efficient strategy, with a full detail of all work steps involved since the preparatory works until the desired measurements in format of graphs and tables. It is fundamental to have a full pre-vision of the system that integrates different systems (static, dynamic and optical systems) and components to anticipate potential difficulties and/or problems in the implementation stage.

(2) Installation works that were performed during the bridge construction. The document "C-Specifications and Procedures" [18], elaborated in the previous phase, was an important guide for the installation works. Namely for a better mutual understanding between the constructor and the monitoring team, and provide all the necessary conditions for the implementation of the system. The monitoring requirement during the bridge construction led to the installation team to explore capabilities such as dynamism, flexibility, adaptability and integration to follow the rhythm imposed by the construction works (often $24 \mathrm{~h} /$ day). After the installation, several tests were needed to consider the system ready and operational in full mode. In a monitoring system like that of Lezíria bridge, it is fundamental to waterproof and seal all the connection boxes and sensors, to maximize the system robustness and durability in a long-term management process.

(3) Data acquisition and treatment was conceived to deliver to the management authority the desire graphs and statistical tables. The reading procedures for normal and alarm modes were established according to the project requirements, and the collected measurements are stored in a remote database linked to the field system via optical cable. The fact that the monitoring system has been operating since the installation of the first sensors has the advantage of a closer checking of the 
construction process, as well as the evaluation of the structural response from the beginning of construction. Since the opening to traffic, the monitoring system has been working in full mode, and periodical reports are delivered to the owner. The possibility of crossing information with the visual inspections can certainly benefit the surveillance and management of the bridge.

\section{Acknowledgements}

As usual for in-situ works, there are many relevant if not decisive personal contributions. It would be impossible and displaced to mention them exhaustively here. Nevertheless, the authors wish to thank to all those who contributed to the success of the implementation of this system, including the LABEST team, the NewMENSUS, the contractor TACE, and the bridge owner, BRISA SA. The first author also expresses thankfulness to the Portuguese Foundation for Science and Technology for the funding of his doctoral studies. 
Table 1 - Executive Project organization (Figueiras et al., 2007a).

\begin{tabular}{|c|c|c|c|c|}
\hline \multirow[b]{2}{*}{ Document } & \multirow{2}{*}{ Objective } & \multicolumn{3}{|c|}{ System installation } \\
\hline & & Before & During & After \\
\hline $\begin{array}{l}\text { Presentation } \\
\text { Document }\end{array}$ & $\begin{array}{l}\text { Project Executive organization; objectives description of each } \\
\text { document. }\end{array}$ & $\checkmark$ & & \\
\hline Project brief & $\begin{array}{l}\text { Monitoring system definition and specifications, namely: } \\
\text { sensors; acquisition systems; communication network; data } \\
\text { treatment and management software. }\end{array}$ & $\checkmark$ & & \\
\hline Contract drawings & $\begin{array}{l}\text { Plans and sections drawings of the monitoring system } \\
\text { implementation, namely: the instrumented sections; sensors; } \\
\text { acquisition nodes; cables path. }\end{array}$ & $\checkmark$ & & \\
\hline $\begin{array}{l}\text { Specifications and } \\
\text { Procedures }\end{array}$ & $\begin{array}{l}\text { Definition, sequence and description of a set of tasks to consider } \\
\text { during the monitoring system installation. }\end{array}$ & $\checkmark$ & & \\
\hline $\begin{array}{l}\text { Observation } \\
\text { reports - Bridge } \\
\text { construction }\end{array}$ & $\begin{array}{l}\text { Biweekly reports with the records obtained during the bridge } \\
\text { construction through time series graphs and summary tables } \\
\text { with the mainly statistical results. }\end{array}$ & & $\checkmark$ & \\
\hline Final report & $\begin{array}{l}\text { Verification of compliance of the monitoring system installed, } \\
\text { including: detailed location of the sensors installed in each } \\
\text { section; table of calibration constants by sensor to convert the } \\
\text { electrical or optical signal to the physical parameters intended to } \\
\text { measure; sensor reference readings on which all measurements } \\
\text { will be based. }\end{array}$ & & $\checkmark$ & \\
\hline $\begin{array}{l}\text { Technical } \\
\text { compilation }\end{array}$ & $\begin{array}{l}\text { Detailed technical specifications of each type of sensor, their } \\
\text { guarantee and certificates of conformity provided by the } \\
\text { manufacturers. }\end{array}$ & & $\checkmark$ & \\
\hline Operations manual & $\begin{array}{l}\text { Software and hardware description of the monitoring system } \\
\text { with: alert levels defined by the designers; operational mode in } \\
\text { terms of service; maintenance plan; recommendations to the } \\
\text { good practice; procedures to detect and correct possible fails. }\end{array}$ & & $\checkmark$ & \\
\hline $\begin{array}{l}\text { Observation } \\
\text { reports - Service } \\
\text { life }\end{array}$ & $\begin{array}{l}\text { Semestral reports with the records obtained during the service } \\
\text { life of the bridge through time series graphs and summary tables } \\
\text { with the mainly statistical results. }\end{array}$ & & & $\checkmark$ \\
\hline
\end{tabular}


Table $2-$ Characteristics and location of measured parameters.

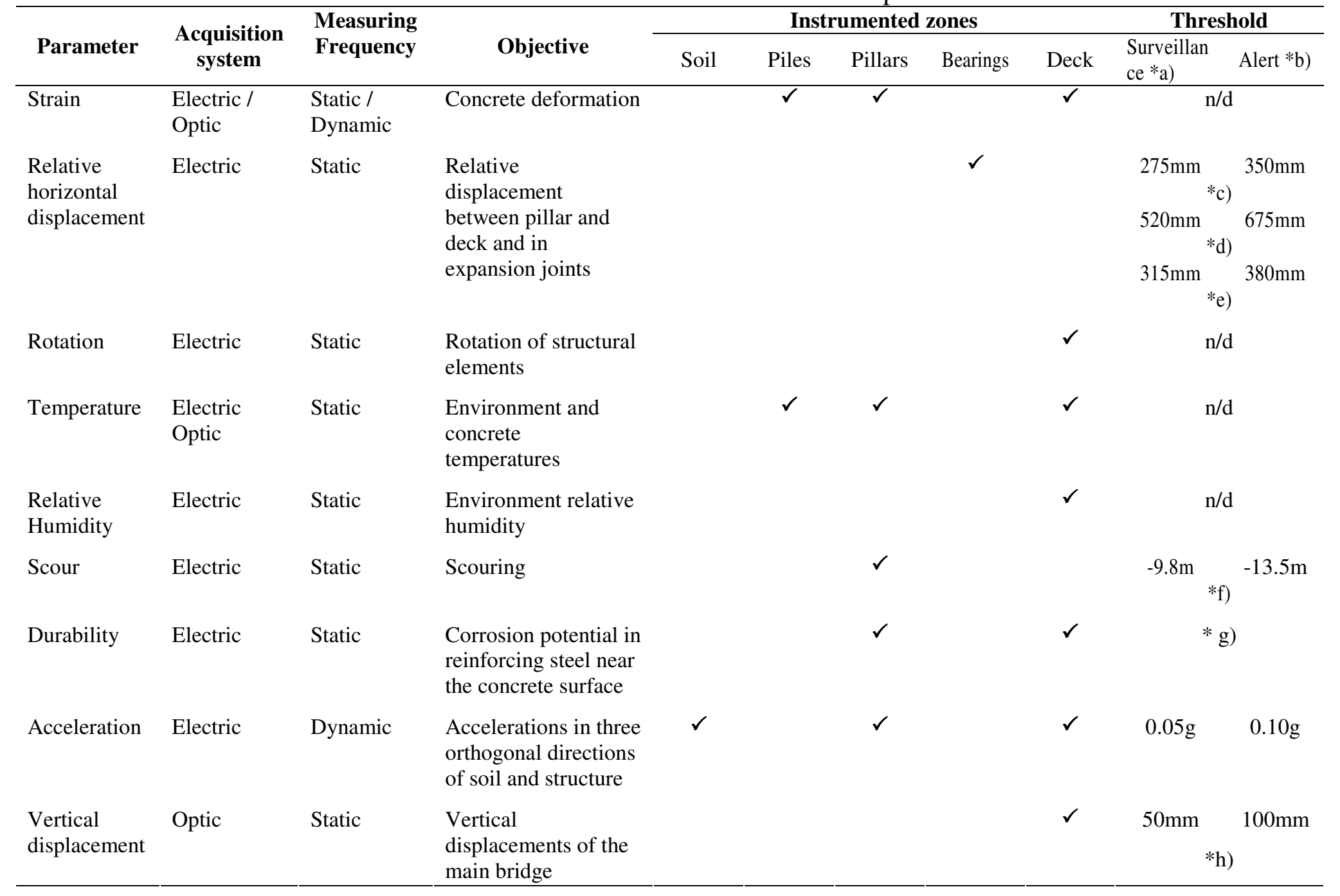


* a) The surveillance levels are determined for the frequent combination of actions, with a limit of L/2500 [10].

* b) The alert levels are determined for the characteristic combination of actions, with a limit of L/1200 for the main bridge and L/1000 to L/600 for the approach viaducts [10].

* c) Maximum values allowed for the joint expansion of the North approach Viaduct.

* d) Maximum values allowed for the joint expansion of the main Bridge.

* e) Maximum values allowed for the joint expansion for the South approach Viaduct.

* f) Maximum values, considering as reference the riverbed elevation at the end of the bridge construction.

* g) The alarm is triggered when the penetration of aggressive agents can predict that the depassivation of the reinforcements will occur in half of the remaining lifetime of the structure, with a minimum of 10 years.

$*$ h) Maximum value allowed for the longest spans of the main bridge. 


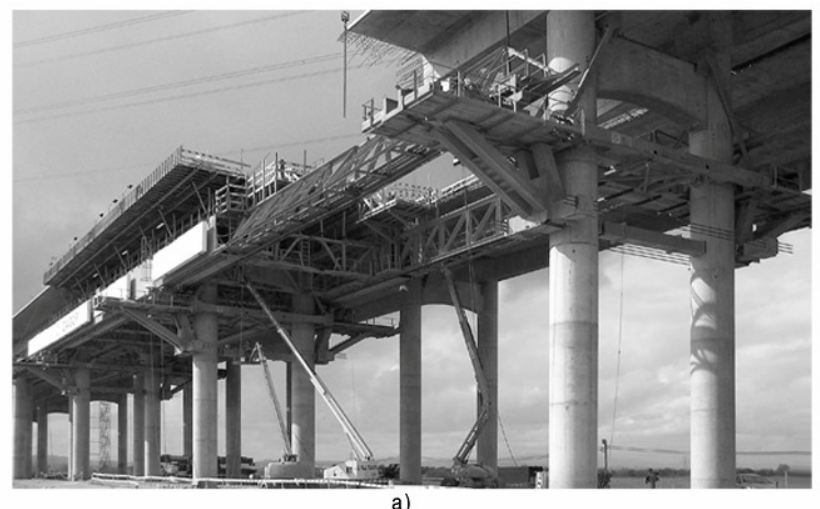

a)

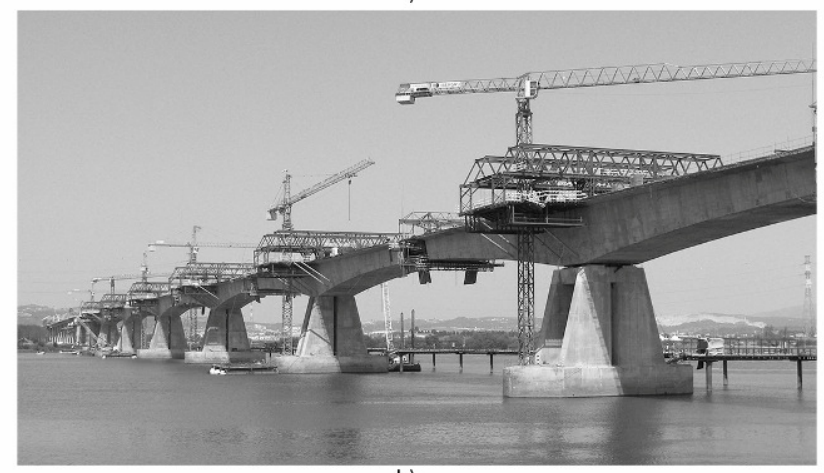

b)

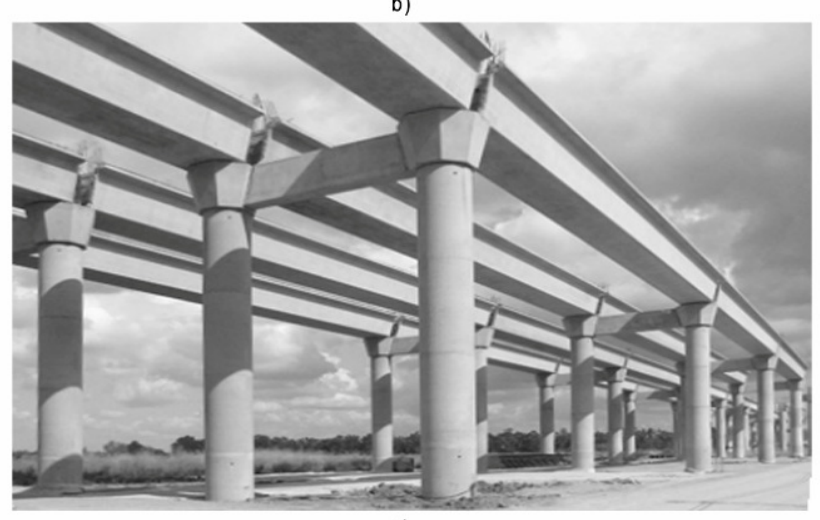

Figure 1 - Lezíria Bridge: a) north approach viaduct, b) main bridge, c) south approach viaduct.
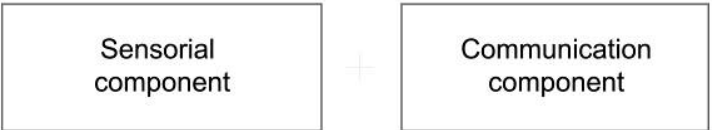

Data treatment and management component

Figure 2 - Components of the monitoring system for the Lezíria bridge.

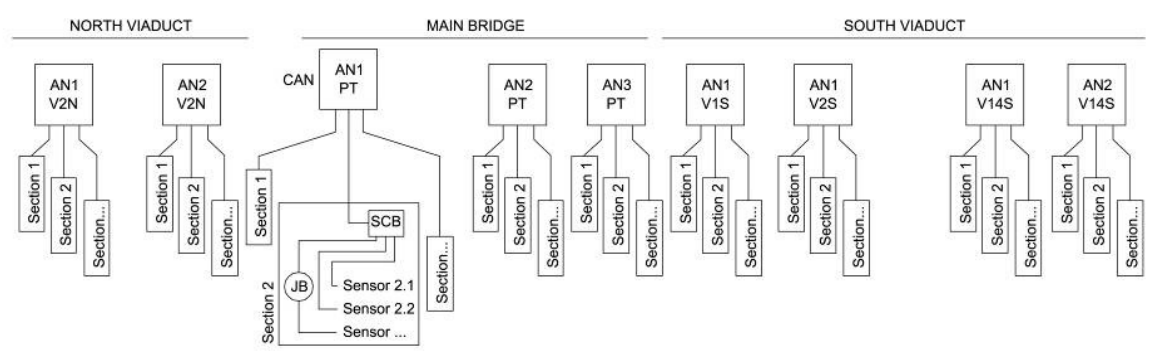

Figure 3 - Architecture of sensorial component. 


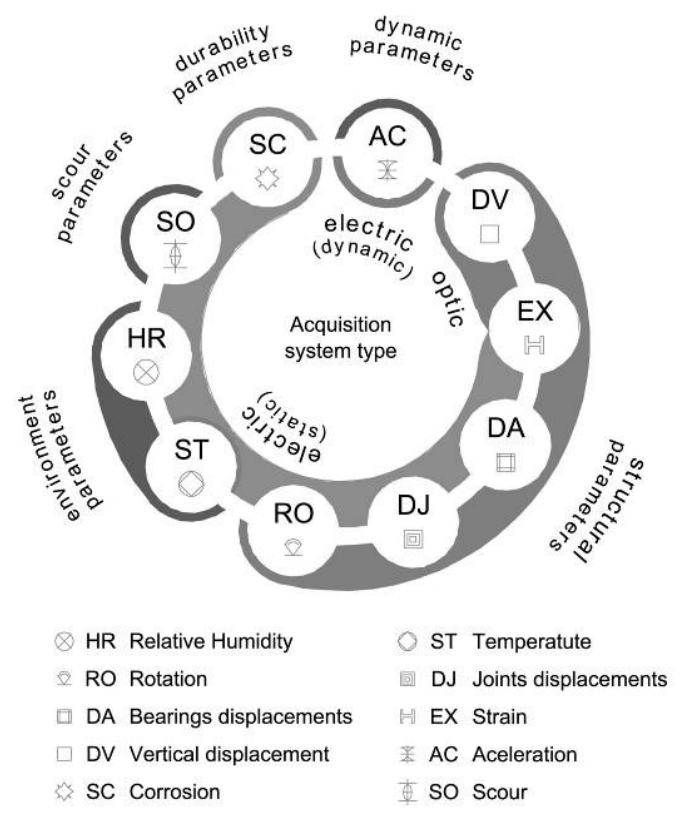

Figure 4 - Constituents of sensorial component.

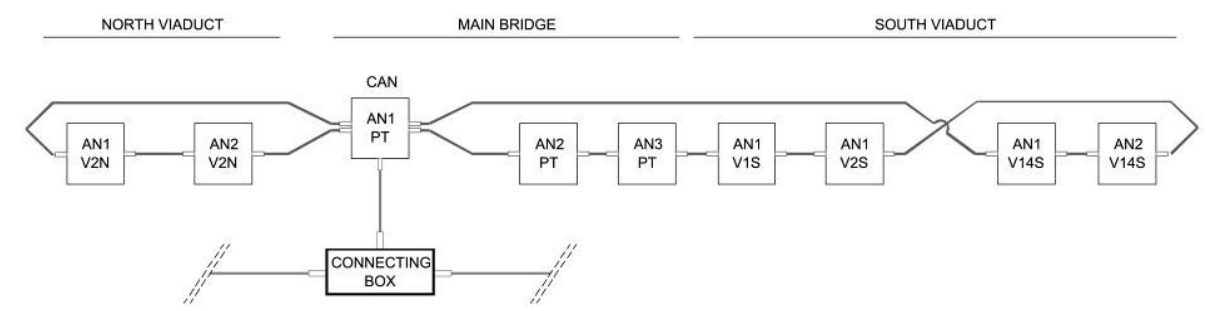

Figure 5-Communication network integrating the various AN's in the CAN.

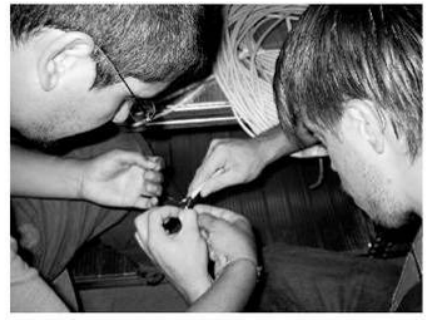

a) sensors verifications

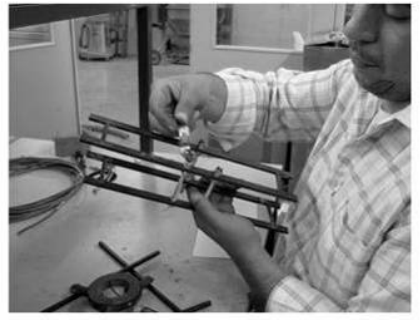

b) sensor holders

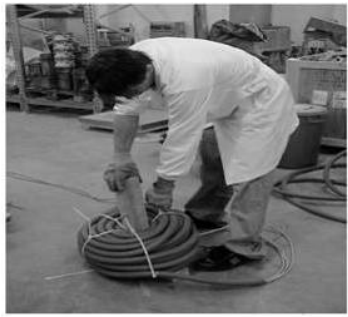

c) cables preparation

Figure 6 - Laboratory preparation works.

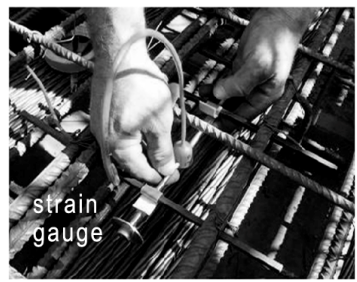

a) embedded sensors

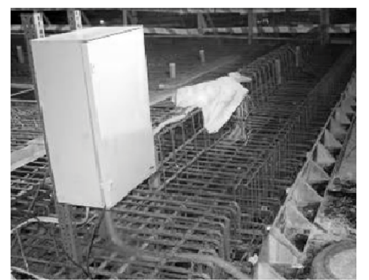

b) provisory Acquisition Node

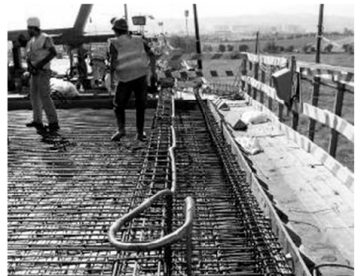

c) provisory cables path

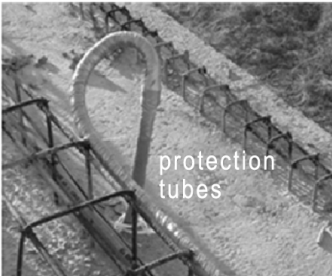

d) provisory conections

Figure 7 - First installation step of the monitoring system. 


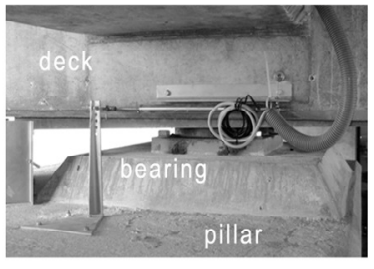

a) external sensors

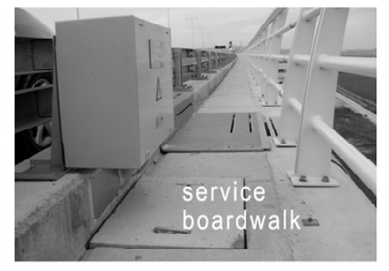

b) permanent Acquisition Node

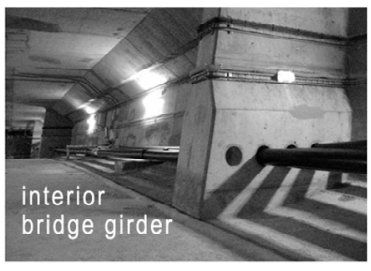

c) permanent cables path

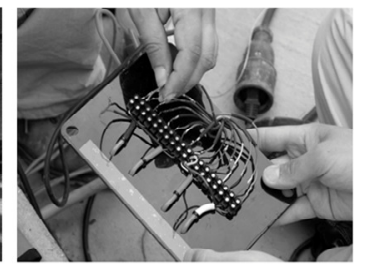

d) permanent conections

Figure 8 - Second installation step of the monitoring system.

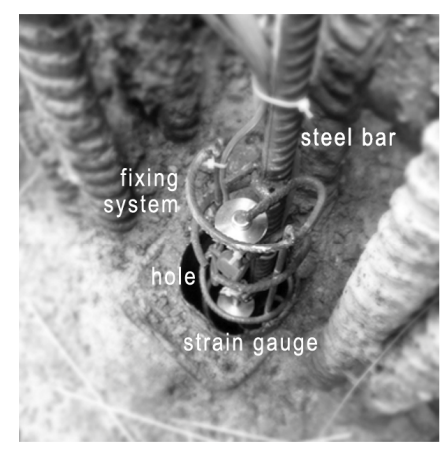

a) strain gauges in pile

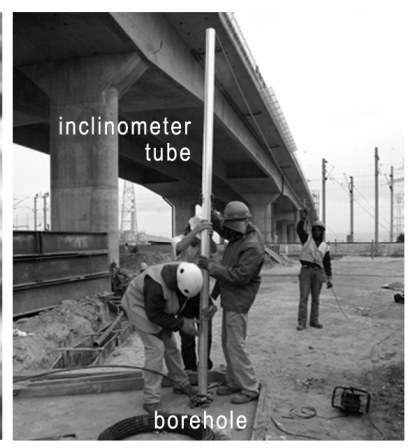

b) soil acelerometer

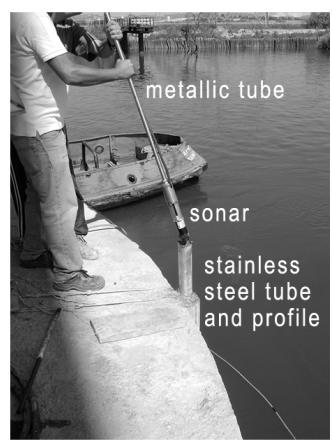

c) sonar protection

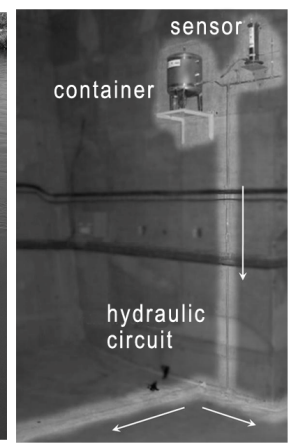

d) hidraulic circuit

Figure 9 - Peculiar tasks of the monitoring system installation.

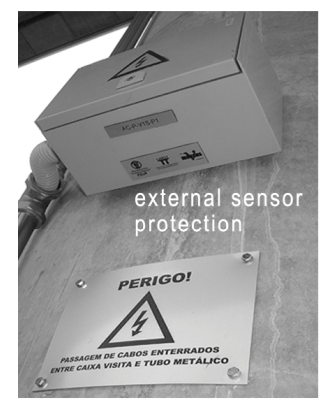

a) identification plates

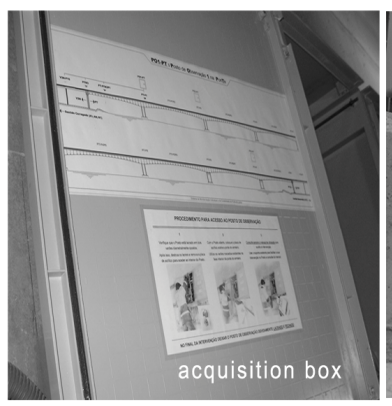

b) user manuals

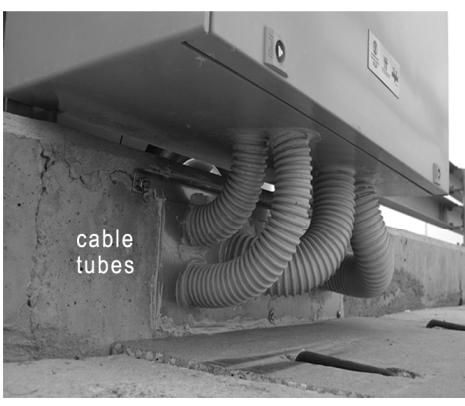

c) waterproofing

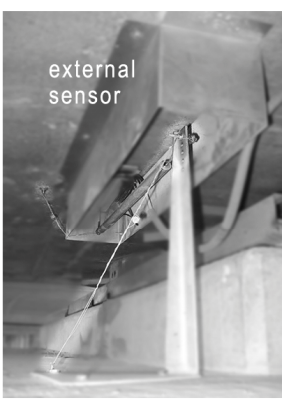

d) system sealing

Figure 10 - Image manual, waterproofing and sealing. 

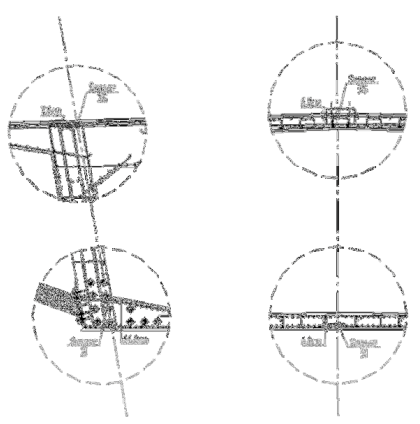

a) sensors localization
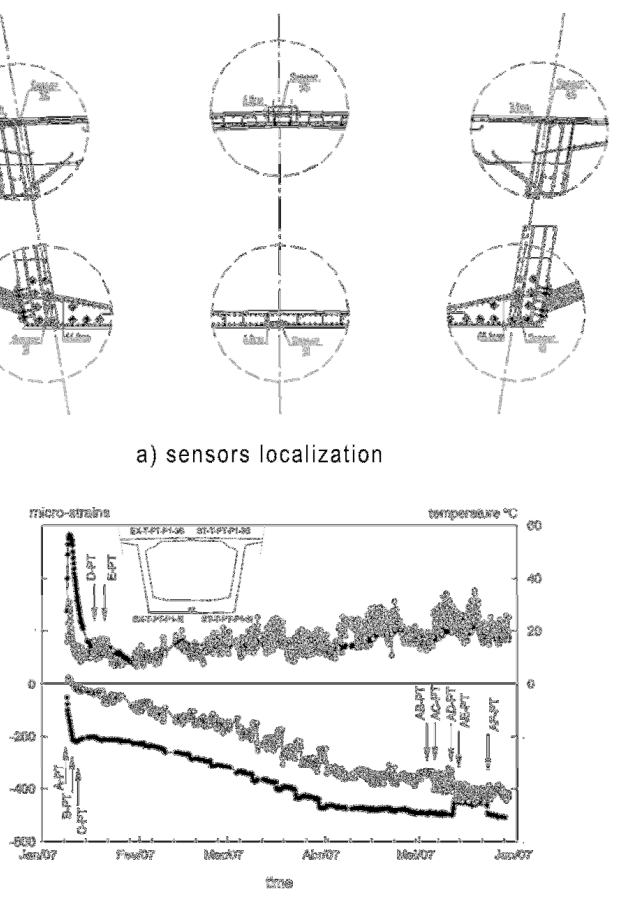

c) time series graph

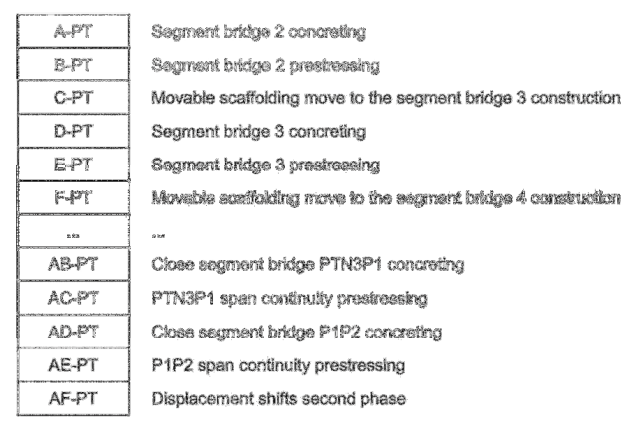

b) events schedule

\begin{tabular}{|c|c|c|c|c|c|}
\hline Amentand & 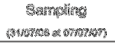 & 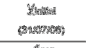 & 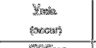 & 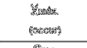 & 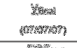 \\
\hline 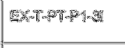 & 3422 & 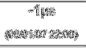 & 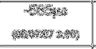 & 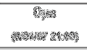 & 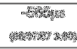 \\
\hline 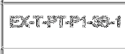 & 3 & 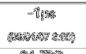 & 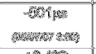 & thes & 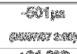 \\
\hline STI & enthes & 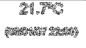 & 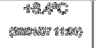 & 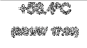 & 4⿴囗. \\
\hline ivite & sis: & 船, & 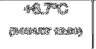 & 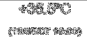 & 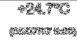 \\
\hline
\end{tabular}

d) statistical information

Figure 11 - Information included in the periodic observation reports during the bridge construction. 


\section{References}

[1] Auweraer, H. V., Peeters, B., 2003. International Research Projects on Structural Health Monitoring: An Overview. Journal of Structural Health Monitoring, 2(4), 341-358.

[2] Minchin Jr, et al., 2006. Best Practices of Bridge System Management - A Synthesis. Journal of Management in Engineering, 22(4), 186-195.

[3] Brito, J., et al., 2002. 'Inspectionability' of bridges. Structural Concrete, the official Journal of the fib, 3(1), 29-34.

[4] Chang, S. P., et al., 2009. Necessity of the bridge health monitoring system to mitigate natural and man-made disasters. Structure and Infrastructure Engineering, 5(3), 173-197.

[5] Pines, D., Aktan, E., 2002. Status of structural health monitoring of long-span bridges in the United States. Progress in Structural Engineering and Materials, 4(4), 372-380.

[6] Bergmeister, K., Santa, U., 2001. Global monitoring concepts for bridges. Structural Concrete, the official Journal of the fib, 2(1), 29-39.

[7] BRITE/EURAM, 1997. SMART STRUCTURES - Integrated Monitoring Systems for Durability Assessment of Concrete Structures [online]. Project N ${ }^{\circ}$ BRPRCT98-0751. Available from: http://smart.ramboll.dk/smart_eu/index.htm [Accessed October 2008].

[8] Wong, K. Y., 2007. Design of a structural health monitoring system for long-span bridges. Structure and Infrastructure Engineering, 3(2), 169-185.

[9] Oliveira, C. B., 2006. New crossing of the Tagus river from Carregado to Lezíria through A10. Ingenium, $n^{\circ} 95$. (in Portuguese)

[10] COBA-PC\&A-CIVILSER-ARCADIS, 2006. Construction of the Tagus Crossing in Carregado Subsection A1/Benavente, of A10 Highway

Bucelas/Carregado/IC3; Volume XV - Structural and Durability Monitoring Plan. Contract of Conception, Design and Construction of Crossing the Tagus in Carregado. Portugal (in Portuguese).

[11] Figueiras J., et al., 2007a. Construction of the Tagus Crossing in Carregado Subsection A1/Benavente, of A10 Highway Bucelas/Carregado/IC3; Structural and Durability Monitoring Executive Project 0 - Presentation. LABEST, Faculty of Engineering, University Porto, Porto. (in Portuguese).

[12] Figueiras J., et al., 2007b. Construction of the Tagus Crossing in Carregado Subsection A1/Benavente, of A10 Highway Bucelas/Carregado/IC3; Structural and Durability Monitoring Executive Project A - Project Brief. LABEST, Faculty of Engineering, University Porto, Porto. (in Portuguese).

[13] Masskant, R., et al., 1997. Fiber Optic Bragg Grating Sensors for Bridge Monitoring. Cement and Concrete Composites, 19(1), 21-33.

[14] Inaudi, D. (1999). "Long-gage fibre Optic sensors for structural monitoring." In P. K. Rastogi (ed.) Optical Measurement Techniques and Applications. Artech House, 1997, 255-275.

[15] Fernando, G. F., et al., 2003. Structural Integrity Monitoring of Concrete Structures via Optical Fiber Sensors: Sensor Protection Systems. Journal of Structural Health Monitoring, 2(2), 123-135.

[16] Rodrigues, C., Félix, C., Figueiras, J.. (2007) "Fiber ANtic Strain Transducer Conception, analisys and calibration." Internal Report, LABEST, Faculty of Engineering, University Porto, Porto. (in Portuguese). 
[17] Figueiras J., et al., 2007e. Construction of the Tagus Crossing in Carregado Subsection A1/Benavente, of A10 Highway Bucelas/Carregado/IC3; Structural and Durability Monitoring Executive Project G - Operations Manual. LABEST, Faculty of Engineering, University Porto, Porto. (in Portuguese).

[18] Figueiras J., et al., 2007c. Construction of the Tagus Crossing in Carregado Subsection A1/Benavente, of A10 Highway Bucelas/Carregado/IC3; Structural and Durability Monitoring Executive Project B - Contract Drawings. LABEST, Faculty of Engineering, University Porto, Porto. (in Portuguese).

[19] Figueiras J., et al., 2007d. Construction of the Tagus Crossing in Carregado Subsection A1/Benavente, of A10 Highway Bucelas/Carregado/IC3;

Structural and Durability Monitoring Executive Project $\mathrm{C}-$ Specifications and Procedures. LABEST, Faculty of Engineering, University Porto, Porto. (in Portuguese).

[20] Rudaz, S., et al., 2006. AC-23-DH Downhole Accelerometer-Installation Instructions - Version 1 [online]. GeoSIG Ldt. Available from: http://www.geosig.com/downloads/manuals/ AC-23DH_Installation_Instructions.pdf [Accessed 16 September 2008]. 